\title{
EL PROCESO DE CREACIÓN Y REPOSICIÓN EN LA COMPAÑÍA DE DANZA ANTONIO NAJARRO DURANTE LA PANDEMIA DE LA COVID-19: ALENTO'
}

THE PROCESS OF CREATION AND REPLACEMENT IN THE ANTONIO NAJARRO DANCE COMPANY

DURING THE COVID-19 PANDEMIC: ALENTO

\author{
Antonio Najarro \\ Compañía de Danza "Antonio Najarro" \\ info@antonionajarro.com
}

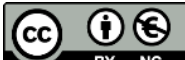

\section{| Resumen |}

Al finalizar su mandato como director del Ballet Nacional de España Antonio Najarro, retomó la actividad de su Compañia de Danza Antonio Najarro durante la pandemia. Ponerla en funcionamiento fue un camino arduo con el cual no se contaba, primero el confinamiento, y una vez concluido este, las restricciones sanitarias mantuvieron la mayoría de los teatros cerrados mermando asi, el desarrollo de las actividades culturales y artísticas. En el presente artículo se pretende abordar cómo se está afrontando el proceso creativo y de reposición de la obra Alento en la compañia, desde una perspectiva distinta a la que se realizaba antes del inicio de la pandemia. La metodología empleada para el desarrollo de dicho proceso es la recopilación de documentos, soportes audiovisuales y ensayos de la compañía.

Palabras clave: Proceso creativo; Alento; Compañia de danza, Pandemia.

\section{Abstract}

At the end of his term as director of the Antonio Najarro National Ballet of Spain, he resumed the activity of his Antonio Najarro Dance Company during the pandemic. Putting it into operation was an arduous path that was not counted on, first the confinement, and once this was concluded, the sanitary restrictions kept most of the theaters closed, thus reducing the development of cultural and artistic activities. This article aims to address how the creative process and the replacement of the Alento work in the company are being faced from a different perspective than the one carried out before the start of the pandemic. The methodology used for the development of this process is the compilation of documents, audiovisual supports and essays of the company.

Keywords: Creative process, Alento, Dance company, Pandemic.

${ }^{1}$ Recibido/Received: 01/|2/202|

Aceptado/Accepted: 21/0I/2022 


\section{| Introducción |}

La Compañía de Danza Antonio Najarro nace en el año 2000 incentivada y creada por el autor de estas palabras, asumiendo el rol de director general y artístico. Durante el periodo 2000/2011 se crearon y produjeron en la compañía cinco espectáculos diferentes formados por las coreografías Tango Flamenco, Flamencoriental, Jazzing Flamenco, Suite Sevilla, Alento, cuya propiedad intelectual de coreografía me corresponde. Es de mérito mencionar que en la compañía ya se trabaja en la planificación del próximo año donde se estrenará la obra titulada Querencia. Desde el equipo completo y desde mi posición intentamos adelantar el trabajo futuro, símbolo del constante compromiso con nuestro público y con el deseo de mantener viva la oferta y el repertorio de esta compañía.

Tras dirigir durante ocho años el Ballet Nacional de España, tomé la decisión de volver a retomar mi propia compañía de danza y reponer mi ballet Alento, una coreografía que creé para el Ballet Nacional de España en el año 2015, y que ahora está siendo interpretada a cargo del equipo de bailarines de mi compañía de danza privada.

Para retomar esta pieza decidí contar con el compositor musical y guitarrista Fernando Egozcue, que coordina la participación sonora del espectáculo, acompañado de un quinteto de músicos que interactúan en directo y generan las aportaciones melódicas sobre las que danzan el cuerpo de baile de la compañía compuesto por 12 intérpretes.

En la reposición de la nueva versión del espectáculo Alento he insertado algunas modificaciones con respecto al estrenado en el año 2015. Siempre he concebido este espectáculo con formato de un solo acto, para así mantener la conexión del espectador con la obra en todo momento. Conservando esta premisa, he añadido dos números coreográficos inéditos que complementan el desarrollo dramático de la obra y dos números musicales nuevos, con la particularidad de ser interpretados en directo por Fernando Egozcue a la guitarra y su quinteto de músicos entre los que se encuentran Laura Pedreira al piano, Martín Bhrun a la percusión, Thomas Potiron al violín y Miguel Rodrigáñez al contrabajo. Pienso que era necesario ceder un espacio -dentro de la pieza coreográfica- a la música flamenca y en especial al trabajo de Egozcue; debido que a la música flamenca le debemos la amplia apertura de fronteras a nivel mundial, que dio paso a que la danza española fuese representada y admirada por todo el mundo, conocida como patrimonio inmaterial de este país (Álvarez Junco, 2001; Navarro García, 2010).

Recordando las palabras del maestro Fernando el de Triana (1935), el flamenco es "gloria natural e intraducible de Andalucía y, por lo tanto, indiscutible y honroso galardón de España" (p. 33). Por su parte, Egozcue aporta a la composición musical unas pinceladas que nos recuerdan al Tango y al Jazz, que se fusionan a la perfección con los ritmos flamencos matriz de mis creaciones. Con este encuentro de estilos se genera un registro sonoro donde se respira raíz, al mismo tiempo que se disfrutan nuevos sonidos. Estamos ante una partitura rítmica y al igual que melódica, llena de sensibilidad, con una 
interesante cualidad descriptiva y sobrecogedora que emociona y enriquece al espectador.

Junto a la coreografía y a la composición musical, el resto del equipo creativo se completa con la importantísima labor que posee la puesta en escena formada por la indumentaria y la iluminación. El diseño y producción del vestuario estuvo a cargo de tres cabezas. Por un lado, contamos con el diseñador de moda Oteyza, uno de los diseñadores españoles de moda masculina que en la actualidad posee mayor proyección internacional. Junto a él trabajó Víctor Muro y un servidor. La adaptación del diseño de luces ha sido creada por Nicolás Fischtel, uno de los iluminadores de espectáculos de danza más importante de nuestro país. Fischtel ha creado para este ballet una exquisita iluminación muy diferente a las estructuras luminotécnicas que normalmente acompañan a los espectáculos danza española. En ella existe una relación directa con el ritmo y el tempo de la música y la coreografía, estableciendo una bella sincronía entre sonido, danza e iluminación que cierra la a la perfección la dramaturgia escénica, aportando movimiento y dinamismo en aquellos momentos donde el ritmo se acentúa.

La propuesta de fusionar varios registros sonoros que recuerden a otros estilos casa a la perfección con la investigación performativa que como coreógrafo llevo realizando durante todos mis años de experiencia. En Alento se recogen los guiños y las partes más potentes de mis obras como Tango flamenco, como Flamencoriental, que eran espectáculos fusión donde se combinaba la música española y el flamenco con el tango argentino, con la música oriental, con el jazz, blues y el soul².

El estreno de este show estaba previsto para el mes de marzo de 2020 en el Mira Teatro de Pozuelo de Alarcón, municipio donde actualmente estamos vinculados como compañía de danza residente. Con anterioridad comencé a organizar toda la preparación de ensayos, así como el resto del equipo creativo comenzaron con el desarrollo de cada campo (música y diseños de indumentaria e iluminación), trabajando en plena intercomunicación en la estructura, escenas y diferentes piezas que componen la obra total. Además, debíamos de rehacer y construir las escenas nuevas que deseábamos añadir a esta nueva versión de Alento. El trabajo con el equipo de bailarines se inició al principio del mes de marzo de ese mismo año, aprovechando las infraestructuras que nos cedían del Centro Coreográfico Canal de Madrid, en aquel momento nos concedieron una residencia en el centro para poder realizar el montaje del espectáculo.

La gran sorpresa llegó cuando, tras dos semanas de duro trabajo entre ensayos, reuniones, colaboraciones entre el equipo creador y gestión de los espectáculos, aparece la invasión de la COVID-19 y el consecuente confinamiento, por lo que tuve que paralizar toda la producción.

\footnotetext{
2 "Alento es una muestra de la versión innovadora de la danza española que persigue Antonio Najarro, integrando sus distintas variantes: flamenco, escuela bolera, folclore y danza estilizada. Entre los ritmos que aporta la partitura no faltan guiños al jazz o al tango" (Castro, 2021).
}

SHJ, 2022, 2(I), pp. 245-252. ISSN: 2792-3967 
Esta situación fue bastante traumática para mí, puesto que en aquel momento se habían iniciado toda la compleja maquinaria de producción del espectáculo y su respectivo coste, aspectos que conlleva el encargo de elementos escénicos y el pago de ensayos de bailarines, cuya actividad se había visto paralizado. Debido al estado de alarma estatal y su orden de confinamiento, nuestro estreno previsto en el Mira Teatro de Pozuelo de Alarcón se tuvo que posponer sin fechas futuras y sin vislumbrar un horizonte favorable.

\section{| Metodología |}

Para poder continuar con el proceso creativo y de reposición de Alento durante el estado de alarma utilicé el método de recopilación de datos, material audiovisuales y ensayos a distancia. El objetivo se centraba en intentar mantener el proceso de producción del espectáculo, a medida de lo posible, para continuar con la construcción performativa y, así, tener la obra preparada en el momento de apertura de teatros. Para ello, estuve grabando vídeos durante el confinamiento donde recogía, exponía y ofrecía pautas sobre la correcta ejecución e interpretación del material coreográfico junto a nuevos elementos dancísticos vinculados a las coreografías que habíamos trabajado en las semanas de presencialidad.

Con estos vídeos planteaba a mi equipo un trabajo pedagógico suministrando explicaciones de los pasos, zapateados, toques de castañuelas y demás elementos coreográficos. Enseguida descubrí que era muy importante ser riguroso y preciso con cada elemento expuesto, cada detalle, estudiando bien la forma de comunicarme con ellos, cuidando mis palabras y mis explicaciones, y de exponer la intensidad y empeño que debe de poseer cada movimiento; teniendo en cuenta que el trabajo artístico a distancia necesita de un trato minucioso que bloquee las posibles interpretaciones subjetivas que cada intérprete pueda tomar.

Este material lo enviaba a los bailarines para que no se olvidaran de la obra y pudieran trabajar en sus casas todo lo que habíamos ensayado en las semanas previas al confinamiento. De manera muy sencilla y orgánica se generó una red de comunicación virtual donde coreógrafo y bailarines interactuábamos a unísono. Sin duda, fue un trabajo muy duro y delicado, para el que no me encontraba preparado, supongo que al igual que muchos de mis compañeros del campo. En este sentido recuerdo las palabras del investigador y coreógrafo Manuel Garzón (2021) que reflexionaba sobre las dificultades del trabajo coreográfico a distancia, cuyo mensaje centraba la mirada en la disyuntiva de esta labor intentando realizar una correcta "modulación de dinámicas, fuerzas, sensaciones y direcciones espaciales, junto al componente 'alma', mediante el que se entretejen emociones, sensaciones, campos semánticos y experiencias y donde todos ellos se unen con una concreta aplicación de la semiótica escénica” (p. 253). Puesto que, en línea con Garzón, el trabajo performativo grupal requiere de contacto físico, de sentir la energía de cada cuerpo tanto a nivel individual como a nivel grupal, para que, de este modo, se puedan conectar emociones. 
La danza y la creatividad en danza necesita de un acercamiento físico que es poco sustituible mediante la esfera digital. Como decía Duncan (2016), sin cuerpo que mueva no puede existir danza, y precisamente ese cuerpo debe de ser dirigido por el director artístico o coreógrafo, que es el encargado de trazar una línea coherente que abarque el movimiento (con su correcta ejecución), la dramaturgia general de la obra y la sincronía entre todos los componentes escénicos. Gracias al increíble desarrollo de las redes sociales (RRSS) en nuestras vidas, hemos establecido una interconexión con las personas de nuestro entorno, amigos, trabajo, conocidos que funciona de manera instantánea. Pienso que esa práctica social ha ayudado a que los trabajos funcionen con mayor ligereza en la coordinación y logística. No cabe duda de que esa actividad ha instaurado aspectos pedagógicos, educativos o de formación sea cual sea el campo tratado; como podemos ver en el desarrollo de las Tecnologías de la Información y la Comunicación (TIC) y las Tecnologías de Aprendizaje y Conocimiento (TAC).

En esta montaña rusa de sensaciones dentro de mi propio hogar donde se mezclaban las preocupaciones de salud y el trabajo, nos anunciaron en el mes de mayo una posible representación en el Teatro del Generalife insertada dentro de la programación del Festival Internacional de Música y Danza de Granada. En ese momento se planteó realizarse en el mes de julio, como pautaba la tradición del encuentro. Esta noticia no ofrecía ninguna seguridad, al contrario, todo era incertidumbre puesto que nadie sabía cómo iba a progresar la pandemia y si en esa fecha ya no habría barreras sociales; pero yo soy una persona optimista e intento por todos los medios que todas las actividades salgan adelante, por lo que nos pusimos a trabajar con mayor actividad, llenos de esperanzas incentivados por la gratificante noticia.

Podría decir que en esta segunda etapa de 'trabajo casero' fue de grandísima ayuda la predisposición de Blanca Li, directora de los Teatros del Canal, así como de Antonio Moral, director del Festival Internacional de Música y Danza de Granada. Gracias a ambos pudimos sacar adelante la preparación de ensayos después del confinamiento, adaptándonos a las restricciones que pautaba la nación y a las que nos debíamos adecuar, tanto nosotros como las necesidades propias de gestión y producción de espectáculos.

Para los ensayos tuvimos que respetar todas las medidas sanitarias impuestas en el Centro Coreográfico Canal, por lo que todos los integrantes del equipo artístico teníamos que estar constantemente haciéndonos pruebas PCR, realizar los ensayos con mascarillas y evitar en la medida de lo posible el contacto entre los bailarines -elemento muy conflictivo dentro de la actividad de la danza-, que era muy complicado dado que en la coreografía hay partes donde se realizan portés (elevaciones realizadas entre bailarines donde uno o varios agentes despegan el centro gravitatorio de otro agente) donde el contacto del bailarín y la bailarina era inevitable. Como código interno se planteó un compromiso de "grupo burbuja" al que no dudaron en aceptar los bailarines. Ellos y yo seríamos los futuros damnificados ante un contagio entre nosotros, por ese motivo se asumió la responsabilidad de no tener contacto con personas ajenas a la compañía durante el periodo de ensayos. 
El Festival Internacional de Música y Danza de Granada nos ayudó económicamente ofertando una cuantía económica destinada al coste total de los gastos de las pruebas PCR que teníamos realizar todos los artistas y técnicos de la compañía. A pesar de todas las restricciones, trabajamos intensamente y el estreno en el mes de julio fue todo un éxito.

Lo más emocionante para mí fue percibir cómo el público que asistió al teatro estaba deseoso de emocionarse a través de un espectáculo de danza, después del encierro de tres meses en nuestras casas. La energía en el patio de butacas era explosiva y desde el escenario sentíamos el calor de los observantes que se manifestó en gratificantes aplausos. Sin duda, fue una retroalimentación de felicidad y ganas de luchar para conseguir la deseada nueva normalidad.

Tras el estreno en Granada hemos podido mostrar Alento en muchos escenarios del país. Las críticas periodísticas avalan la buena recogida y valoración del público de esta obra engendrada bajo los latigazos de la COVID-19. Un ejemplo es la publicación de Lessey (2020) en el periódico digital ElFarodeCeuta donde expone: "el espectáculo ha dejado un mensaje positivo, un mensaje alentador, un mensaje alegre a los ceutíes, ese que se ha empeñado en dejar su creador Antonio Najarro, sobre todo tras los momentos difíciles que hemos vivido por la pandemia". Por su parte, en Artezblai (2020), el periódico de las Artes Escénicas publicaba “Alento es un espectáculo coproducido por los Teatros del Canal que se pondrá en escena tras un difícil y costoso proceso de organización y tramitación para conseguir que los bailarines y músicos hayan podido ensayar juntos en esta 'nueva normalidad"'. Sin duda, muy especial es para mí la publicación del periódico digital Granadahoy firmada por Martínez Rosado (2020) el día del estreno de la obra en Granada. En ella, Rosado transcribe una entrevista en la que pude desahogar mis anhelos y mi positividad para el futuro cercano; la publicación se titula "Estrenar este espectáculo en este momento es casi un milagro" y efectivamente así lo siento, así lo viví y así lo expreso. Fue un proceso agónico, de incertidumbre, de esperanzas y de plantear ideas que cocaban contra la pared. Utilizando la danza para olvidarme del virus, de los problemas, era mi propia terapia que intentaba contagiar a mi gente cercana, porque "bailar es una conducta que ha estado presente en el ser humano desde siempre, ya sea como movimientos espontáneos o como complejos bailes y coreografías, pues es una actividad altamente motivante y con un efecto catártico" (Mejías, 2009, p. 17). Y efectivamente, así es, la cultura regenera, ayuda a evolucionar, forma y construye. Todo gracias a la cultura que consigue reconfortarnos en los momentos más complicados.

\section{| Conclusión |}

Todos los bailarines, músicos y técnicos de la compañía hicimos un trabajo en el que no solo había una buena predisposición, sino en el que teníamos la sensibilidad y la emoción a flor de piel, nos dimos cuenta de que nuestra profesión, a pesar de lo dura y sacrificada que es, es maravillosa. 
Tras estar tres meses encerrados en nuestras casas, sin tener espacio físico para poder dar rienda suelta a nuestra imaginación a través del movimiento, sin poder tomar clases presenciales, ni poder zapatear, tocar las castañuelas, saltar, dar piruetas, etc. Pudimos valorar aún más el momento en que podemos hacerlo.

Fue muy impactante sentir la perdida y el vacío de una situación inesperada que fractura completamente los planes establecidos. Sin embargo, encontrar las herramientas para solventarla a modo individual, y se podría decir que con un formato 'casero', me hizo crecer y confiar en las destrezas adquiridas durante tantos años de trabajo.

Para mí, personalmente, ha sido uno de los retos más importantes que he tenido que afrontar en mi vida, con recursos personales he tenido que lograr poner en pie un espectáculo de gran formato en momentos muy difíciles, logrando ser la primera compañía de danza de gran formato en estrenar después de la pandemia.

\section{Referencias}

Álvarez Junco, J. (2001). Mater dolorosa. La idea de España en el siglo XIX. Madrid, Taurus.

Artezblai. (2020). Antonio Najarro estrena una nueva versión del espectáculo 'Alento' [on line]. Publicado el 6 de julio de 2020.

Disponible en http://www.artezblai.com/artezblai/antonio-najarro-estrena-una-nuevaversion-del-espectaculo-alento.html

Castro, A. (2021). 'Alento' en Madrid en Danza. Madriddiario [on line]. Publicado el 6 de mayo de 2021. Disponible en https://www.madridiario.es/alento-madrid-danza

Duncan, I. (2016). Mi vida. L. Calvo (traducción). Editorial Losada, Buenos Aires.

Garzón, M. (2021). Procesos creativos y su afectación tras la COVID-19. Ventana Abierta (2020), trabajar con cuerpos físicos a distancia. Studia Humanitatis Journal, 1 (1), PP. 225-233. ISSN: 2792-3967.

Disponible en https://studiahumanitatisjournal.com/revista/index.php/shj/article/view/24

Lessey, P. (2021). Antonio Najarro y su 'Alento' impresionan al público ceutí. ElFarodeCeuta [on line]. Publicado el 3 de septiembre de 20201.

Disponible en https://elfarodeceuta.es/antonio-najarro-alento-impresionan-publicoceuti/?fbclid=IwAR3RAiacDpvtAMwHQAH79n6wnWHSviOxWdtifdMKBxbneFRLWk16DUfXSs

Martínez Rosado, C. (2021). "Estrenar este espectáculo en este momento es casi un milagro”. GranadaHoy [on line]. Publicado el 11 de julio de 2020. Disponible en 
https://www.granadahoy.com/festival_internacional_de_musica_y_danza/Antonio-

Najarro-estrenar-espectaculo_0_1481552013.html

Megías, M. I. (2009). Optimización en procesos cognitivos y su repercusión en el aprendizaje de la danza [Tesis doctoral]. Universidad de Valencia. Valencia

Navarro García, J. L. (2010). Historia del baile flamenco (Vol. I). Sevilla: Signatura.

Triana, F. (1935). Arte y artistas flamencos. Imprenta Helénica, Madrid.

\section{Nota biográfica}

Antonio Najarro es bailarín y coreógrafo, formado por los más prestigiosos maestros de danza en todos los estilos. Distinguido con importantes galardones, es uno de los coreógrafos de mayor proyección internacional. Fue director del Ballet Nacional de España y actualmente dirige su propia compañía. A lo largo de su sobresaliente trayectoria profesional, ha abordado grandes proyectos pedagógicos, de acción social, moda, pintura y deporte, dando una gran visibilidad al mundo de la danza fuera de sus públicos habituales. Lo ha hecho manteniendo vivo, y ampliando, el repertorio tradicional, al tiempo que abriendo vías de creación innovadoras y vanguardistas. Su compañía de danza fue la primera en estrenar, con gran éxito de público y prensa, el primer espectáculo de danza española de gran formato en plena pandemia. 